Research Article

\title{
Investigations on Engineering Properties of Solidified/Stabilized Pb-Contaminated Soil Based on Alkaline Residue
}

\author{
Fusheng Zha $\left(\mathbb{D}\right.$, Dongdong Pan, Long Xu, Bo Kang, Chengbin Yang $\mathbb{D}^{\text {, }}$, and Chengfu Chu \\ School of Resource and Environmental Engineering, Hefei University of Technology, Hefei 230009, China \\ Correspondence should be addressed to Chengbin Yang; yangchengbin@hfut.edu.cn
}

Received 18 April 2018; Accepted 6 June 2018; Published 19 September 2018

Academic Editor: Annan Zhou

Copyright (C) 2018 Fusheng Zha et al. This is an open access article distributed under the Creative Commons Attribution License, which permits unrestricted use, distribution, and reproduction in any medium, provided the original work is properly cited.

\begin{abstract}
Solidification/stabilization (S/S) has been considered as one of the most effective techniques for remediation of the heavy metalcontaminated sites. Among various binders adopted in S/S, alkaline residue (AR) could be considered as a new binder to treat heavy metal-contaminated soil due to its strong adsorptive capacity for heavy metal ions. So in this paper, the strength, leaching, and microstructure characteristics of the solidified/stabilized $\mathrm{Pb}$-contaminated soil by using alkaline residue are systematically investigated. Test results present that the unconfined compressive strength (UCS) of the treated soil will increase, while the leached $\mathrm{Pb}^{2+}$ concentration will decrease, with the increase of the alkaline residue content in the specimen. The UCS increases significantly with the curing time increasing during the initial 28 days, after which the UCS of the specimen becomes stable. The leached $\mathrm{Pb}^{2+}$ concentration decreases significantly at the initial 28 days followed by a stable trend with curing time increasing. The UCS decreases and the leached $\mathrm{Pb}^{2+}$ concentration increases with the increase of the initial $\mathrm{Pb}^{2+}$ concentration in the specimen. The microstructural analysis performed by scanning electron microscope (SEM) showed that the increase of the alkaline residue content and curing time will result in more hydration products and densified microstructure, which could effectively improve the engineering properties of the specimen.
\end{abstract}

\section{Introduction}

Widespread contamination of soil with heavy metal is one of the most severe environmental problems that can seriously deteriorate the environmental quality and human health. Remediation techniques are massively proposed for remediation of the heavy metal-contaminated site $[1,2]$, in which the stabilization/solidification (S/S) technique is intensively accepted for its efficiency, convenience, and costeffectiveness. According to the remediation mechanism (including adsorption, encapsulation, precipitation, and complexation), selection of the binder for improvement of the strength and leaching characteristics is of great importance to the application of the stabilization/solidification technique [3-10].

Alkaline residue, the by-product generated from the manufacturing alkaline industry, attracts attentions in the $\mathrm{S} / \mathrm{S}$ technique recently. The extremely fine particles consisted in alkaline residue would result in high specific surface area and strong adsorptive capacity, which are beneficial for removal of heavy metal ions in the contaminated site. In addition, hydration products could be generated from the complicated interactions between the alkaline residue and soil, which will improve the leaching characteristics of the treated soils due to the adsorption and encapsulation mechanisms. Components like calcium oxide and aluminum oxide contained in AR can be the framework alongside with the hydration products generated from the hydration reaction, which will enhance the strength of the specimen. Based on the experimental investigations, Yan et al. [11] reported that the addition of alkaline residue in the contaminated soils could significantly reduce the leachability of $\mathrm{Pb}^{2+}$ to an acceptable level and the removal efficiency strongly depended on the $\mathrm{pH}$ value in the soils. The adsorption characteristics of the alkaline residue on heavy metal ions were also investigated by Cao et al. [12], in which the adsorption capacity of alkaline residue was confirmed to be susceptible to the $\mathrm{pH}$, temperature, and the initial 
concentration of heavy metal ions in the soils. Jin et al. [13] confirmed the remarkable adsorption characteristics of the alkaline residue and the important roles of the temperature and $\mathrm{pH}$ value played during the adsorption process. Additionally, Sun et al. [14] investigated the engineering properties of the expansive soil treated by using alkaline residue. Test results indicated remarkable improvement of the basic properties (including the relative density, liquid/plastic limit, and expansive potential) and strength characteristic of the treated soil, which was supported by the Wang et al. [15].

As mentioned above, alkaline residue is normally regarded as an effective binder because of its significant absorption characteristic in previous researches. Comprehensive investigations on the basis of engineering and environmental characteristics, as well as the microcosmic mechanism, are rarely reported. In the present work, the UCS and leaching characteristics, as well as the microstructure analysis of the alkaline residue-treated contaminated soil, are experimentally investigated to reveal the remediation efficiency and mechanism.

\section{Testing Materials and Procedures}

2.1. Testing Materials. The tested soil was excavated from a construction site at depth of $3.0-4.5 \mathrm{~m}$ in Wuhu City, Anhui province, which is in the eastern part of China. The basic physical properties and the major chemical components determined by the X-ray fluorescence (XRF) technique are listed in Tables 1 and 2, respectively. As can be seen, the tested soil is a kind of plastic clay with $\mathrm{SiO}_{2}$ and $\mathrm{Al}_{2} \mathrm{O}_{3}$ contents more than $80 \%$. The maximum dry density and the optimal water content are $1.81 \mathrm{~g} / \mathrm{cm}^{3}$ and $18.5 \%$, respectively, according to the compaction test (Figure 1), which is conducted following the Test Methods of Soils for Highway Engineering (JTGE 40-2007) [16].

The alkaline residue adopted in the present work is collected from an ammonia alkali factory in Weifang, Shandong province, which is in the eastern part of China. The major chemical components determined by the XRF technique are presented in Table 3. It is clear that $\mathrm{CaO}$ takes dominant proportion in the alkaline residue, while $\mathrm{MgO}$, $\mathrm{SiO}_{2}$, and $\mathrm{Al}_{2} \mathrm{O}_{3}$ also take a relatively large amount. As shown in Figure 2, the particle size of AR is mainly in the range of $1-10 \mu \mathrm{m}$, which confirms the large specific surface area and strong adsorptive capacity of the alkaline residue adopted in the present work.

In the present work, lead-contaminated soil is aimed for remediation due to its serious hazard and typical distribution in China. Analytical grade $\mathrm{Pb}\left(\mathrm{NO}_{3}\right)_{2}$ is selected as the heavy metal contaminants due to its high solubility, as well as the low interference of $\mathrm{NO}_{3}{ }^{-}$ions to the hydration process $[17,18]$.

\subsection{Testing Procedures}

2.2.1. Specimen Preparation. In specimen preparation, the $\mathrm{Pb}^{2+}$ concentrations $(\mathrm{mg} / \mathrm{kg})$ of $0.1 \%, 0.5 \%, 1 \%, 2 \%$, and $3 \%$ and alkaline residue contents of $0 \%, 10 \%, 20 \%, 30 \%, 40 \%$, and $50 \%$ are designed in the present work. The contaminant

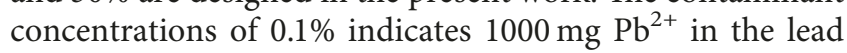
nitrate for $1 \mathrm{~kg}$ dry soil and is denoted as $\mathrm{Pb} 0.1$. The alkaline residue content of $10 \%$ is the mass ratio of alkaline residue to the dry soil and is denoted as AR10. After oven-drying at $105^{\circ} \mathrm{C}$ for 24 hours, the soil and alkaline residue were ground into powders and sized through $2 \mathrm{~mm}$ and $0.5 \mathrm{~mm}$ sieve, respectively. Then the soil and alkaline residue powders were mixed with the $\mathrm{Pb}\left(\mathrm{NO}_{3}\right)_{2}$ and deionized water at the designed proportions. After this, the mixtures were put into a compaction mould and statically compacted into targeted cylindrical specimens with a dimension of $100 \mathrm{~mm}$ in height, $50 \mathrm{~mm}$ in diameter, and a dry density of $1.72 \mathrm{mg} / \mathrm{cm}^{3}$, which equaled to the $95 \%$ of the maximum dry density. Finally, the prepared specimens were extruded from the mould and cured under standard curing conditions with temperature of $20 \pm 1^{\circ} \mathrm{C}$ and relative humidity of $95 \%$ for $0 \mathrm{~d}, 1 \mathrm{~d}, 7 \mathrm{~d}, 14 \mathrm{~d}$, $28 \mathrm{~d}$, and $90 \mathrm{~d}$.

2.2.2. Unconfined Compressive Strength (UCS) Test. After the completion of the curing, the unconfined compressive strength tests were performed on the specimens following the Standard Test Method for Unconfined Compressive Strength of Cohesive Soil (ASTM D2166-06) [19]. The YHS2 UCS testing apparatus at a vertical strain rate of $1 \% / \mathrm{min}$ was adopted in the test, and three parallel specimens were tested in each test with the average value as the representative one.

\subsubsection{The Toxicity Characteristic Leaching Procedure (TCLP).} The leachability of heavy metals from the stabilized soils was determined using the toxicity characteristic leaching procedure (TCLP) in accordance with the U.S EPA Method 1311 [20]. The prepared specimen was crushed into pieces with the size smaller than $9.5 \mathrm{~mm}$. The leachant with $\mathrm{pH}$ value of $2.88 \pm 0.05$ was prepared by diluting $5.7 \mathrm{ml}$ acetic acid (HAC) into $1 \mathrm{~L}$ deionized water. Then, $12.5 \mathrm{~g}$ crushed specimen and $250 \mathrm{ml}$ leachant (solid-to-liquid ratio of $1: 20$ ) were mixed in a polythene bottle and vibrated at the rate of $180 \mathrm{rpm}$ for $18 \mathrm{~h}$. After this, the leachate was filtered through $0.45 \mu \mathrm{m}$ filter membrane, and the $\mathrm{pH}$ value and $\mathrm{Pb}^{2+}$ concentration in the leachate were measured to analyze the leaching characteristic of the treated specimen.

2.2.4. Microstructural Test. The prepared specimen was cut into small pieces with sizes around $5 \mathrm{~mm} \times 5 \mathrm{~mm} \times 3 \mathrm{~mm}$. Surface of the samples should be cleaned and polished carefully before freeze-drying in vacuum condition. Then, conductive coating was done to prepare the standard samples for the scanning electron microscope (SEM) test with the help from a professional institution.

\section{Results and Discussion}

3.1. Effects on the UCS of the Solidified/Stabilized Specimen. The UCS of the solidified/stabilized specimen is investigated with consideration of different influencing factors. The 
TABLE 1: Basic physical properties of the tested soil.

\begin{tabular}{lcccccccc}
\hline $\begin{array}{l}\text { Water } \\
\text { content (\%) }\end{array}$ & $\begin{array}{c}\text { Specific } \\
\text { gravity }\end{array}$ & $\begin{array}{c}\text { Void } \\
\text { ratio }\end{array}$ & $\begin{array}{c}\text { Degree of } \\
\text { saturation (\%) }\end{array}$ & $\begin{array}{c}\text { Liquid } \\
\text { limit }(\%)\end{array}$ & $\begin{array}{c}\text { Plastic } \\
\text { limit }(\%)\end{array}$ & $\begin{array}{c}\text { Plastic } \\
\text { index }\end{array}$ & Cohesive strength (kPa) & Internal friction angle $\left({ }^{\circ}\right)$ \\
\hline 20.18 & 2.72 & 0.718 & 94 & 41.7 & 23.1 & 18.6 & 65 & 13.2 \\
\hline
\end{tabular}

TABLE 2: Major chemical components of the tested soil.

\begin{tabular}{lcccccccccc}
\hline Component & $\mathrm{CaO}$ & $\mathrm{MgO}$ & $\mathrm{SiO}_{2}$ & $\mathrm{Al}_{2} \mathrm{O}_{3}$ & $\mathrm{Fe}_{2} \mathrm{O}_{3}$ & $\mathrm{P}_{2} \mathrm{O}_{5}$ & $\mathrm{TiO}_{2}$ & $\mathrm{Na}_{2} \mathrm{O}$ & $\mathrm{K}_{2} \mathrm{O}$ & $\mathrm{MnO}$ \\
\hline Content (\%) & 0.81 & 2.04 & 60.93 & 20.77 & 9.21 & 0.11 & 1.25 & 0.52 & 3.94 & 0.12 \\
\hline
\end{tabular}

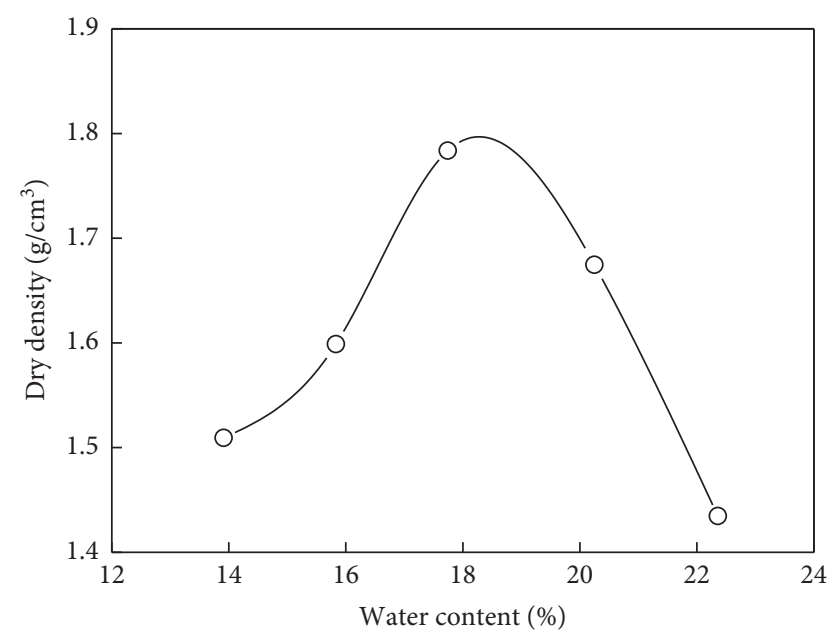

Figure 1: Compaction curve of the tested soil.

TABle 3: Major chemical components of the alkaline residue.

\begin{tabular}{lcccccccccccc}
\hline Component & $\mathrm{CaO}$ & $\mathrm{MgO}$ & $\mathrm{SiO}_{2}$ & $\mathrm{Al}_{2} \mathrm{O}_{3}$ & $\mathrm{~F}$ & $\mathrm{Fe}_{2} \mathrm{O}_{3}$ & $\mathrm{P}_{2} \mathrm{O}_{5}$ & $\mathrm{SO}_{3}$ & $\mathrm{TiO}_{2}$ & $\mathrm{Na}_{2} \mathrm{O}$ & $\mathrm{K}_{2} \mathrm{O}$ & $\mathrm{Cl}$ \\
\hline Content (\%) & 62.81 & 12.5 & 10.2 & 9.00 & 2.47 & 1.31 & 0.40 & 0.3 & 0.24 & 0.23 & 0.17 & 0.16 \\
\hline
\end{tabular}

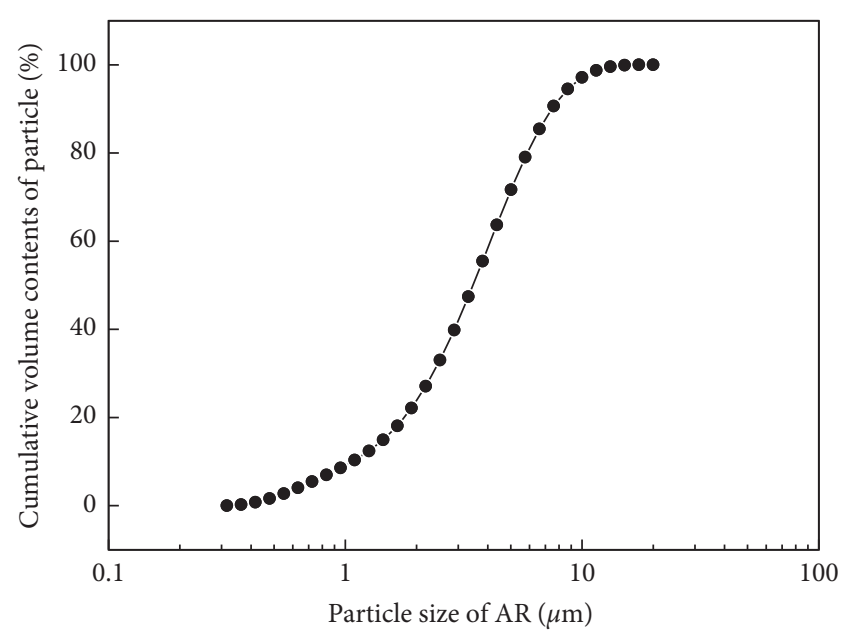

FIgURE 2: Curves of particle size analysis of AR.

evolutions of the UCS with the alkaline residue contents are typically shown in Figure 3.

Curves in Figure 3 showed significant increase of the UCS with incorporation of the alkaline residue into the specimen. Such improvement of the strength characteristic by adding alkaline residue is attributed to the formation of hydration products like $\mathrm{CaO} \cdot \mathrm{SiO}_{2} \cdot n \mathrm{H}_{2} \mathrm{O}(\mathrm{C}-\mathrm{S}-\mathrm{H})$ and $\mathrm{CaSiO}_{3} \cdot \mathrm{CaCO}_{3} \cdot \mathrm{Ca}(\mathrm{OH})_{2} \cdot n \mathrm{H}_{2} \mathrm{O}$ arising from the reactions between the $\mathrm{CaCO}_{3}, \mathrm{Ca}(\mathrm{OH})_{2}$, and $\mathrm{SiO}_{2}[14,15]$. Furthermore, the alkaline environment created by the alkaline residue could promote the hydration reaction and produce more hydration products. Existence of these hydration products decreases the porosity and increases the density and integrity of the specimen, which lead to the increase of the UCS. Additionally, calcium compounds like $\mathrm{CaCO}_{3}$ contained in alkaline residue could form framework in the soil resulting in the improvement of the strength as well $[14,15]$.

As shown in Figure 3, the significant effect of the curing time on the UCS can be preliminarily observed after the comparison of diagrams (a) and (b). In further analysis, the evolutions of the UCS with the curing time are presented in Figure 4.

Results in Figure 4 show that the UCS of the solidified/ stabilized specimen increases with the curing time increasing. A notable increasing magnitude of 38\%-47\% can be observed before 28-day curing. After this, the evolution of 


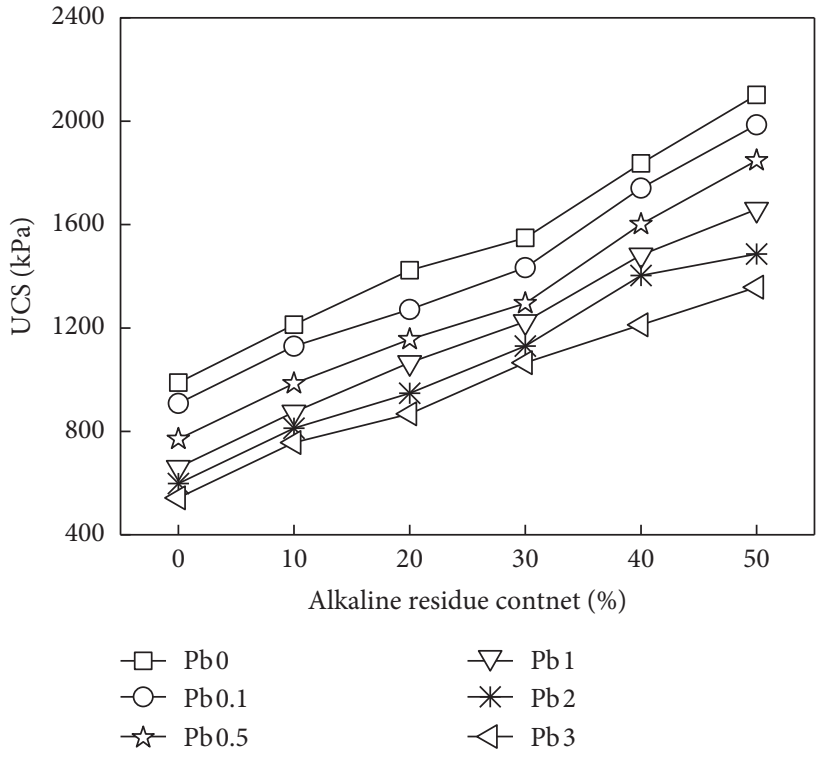

(a)

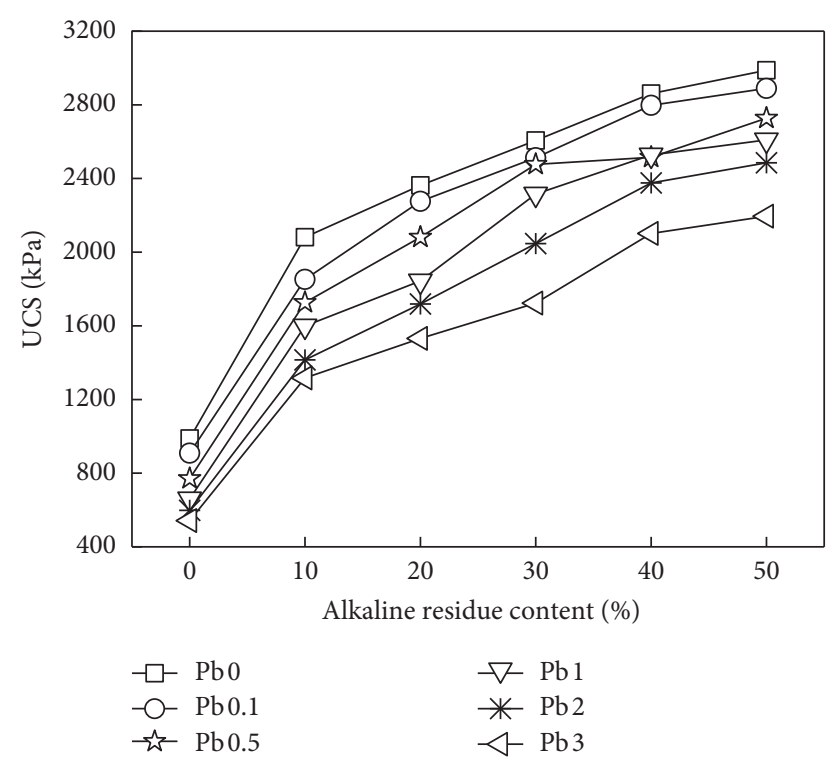

(b)

FIGURE 3: Evolutions of the UCS with the alkaline residue content of the specimen. Curing times of (a) $0 \mathrm{~d}$ and (b) $28 \mathrm{~d}$.

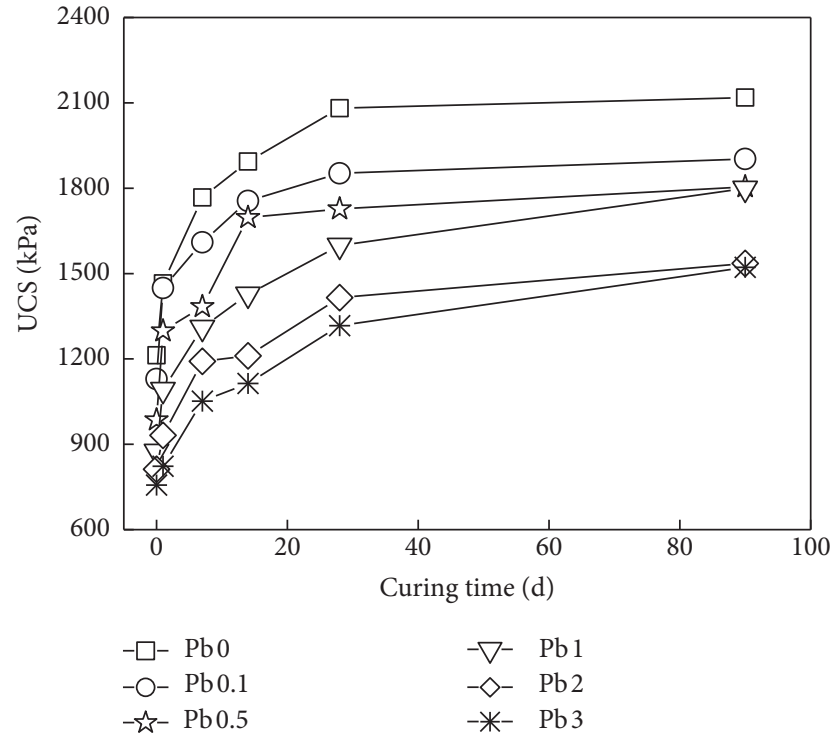

(a)

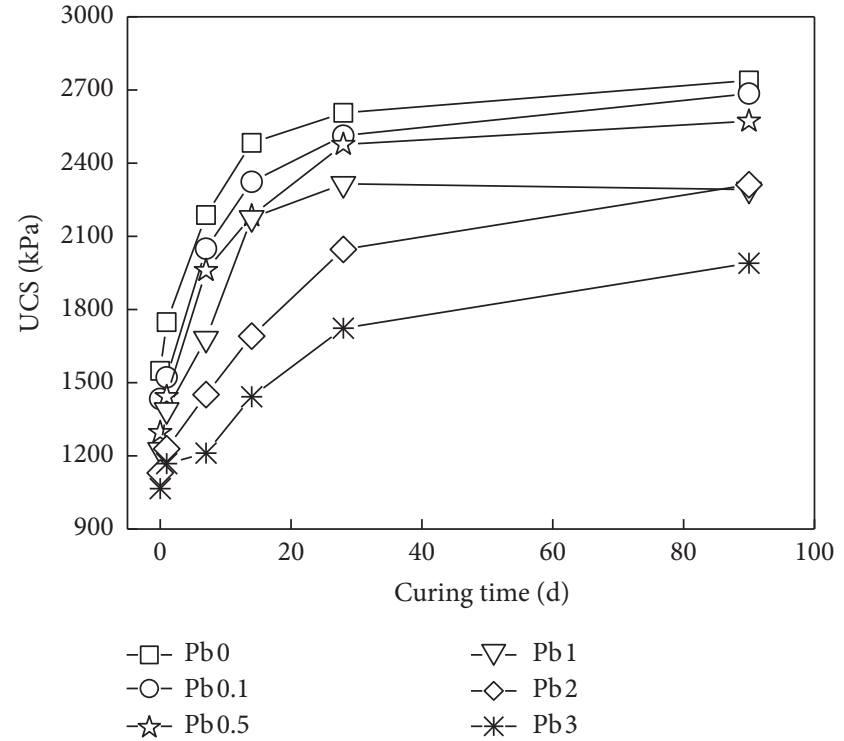

(b)

FIgURE 4: Evolutions of the UCS with the curing time of the specimen. Alkaline residue contents of (a) $10 \%$ and (b) $30 \%$.

the UCS becomes stable with a slight increase in magnitude until 90 -day curing is reached. As described in previous research, the improved strength of the specimen with curing time is attributed to the continuous formation of the hydration products during the hydration process. The pore space in the specimen can be filled, and the solid particles can be encapsulated by these hydration products, which contribute to the improvement of the strength. However, during the later period of the curing (after 28 days in the present work), hydration is fully developed and pores in the specimen are filled by the hydration products at a large proportion. Then the microstructural variation of the specimen becomes limited resulting in relatively stable growth trend of the strength during this stage.

Results in Figure 4 also implied a significant effect of the initial $\mathrm{Pb}^{2+}$ concentration on the UCS of the specimen. For analysis in details, evolutions of the UCS with the initial $\mathrm{Pb}^{2+}$ concentration are depicted in Figure 5.

As shown in Figure 5, the increase of the initial $\mathrm{Pb}^{2+}$ concentration in the specimen leads to a notable decrease of the UCS. This is because the reactions between the 


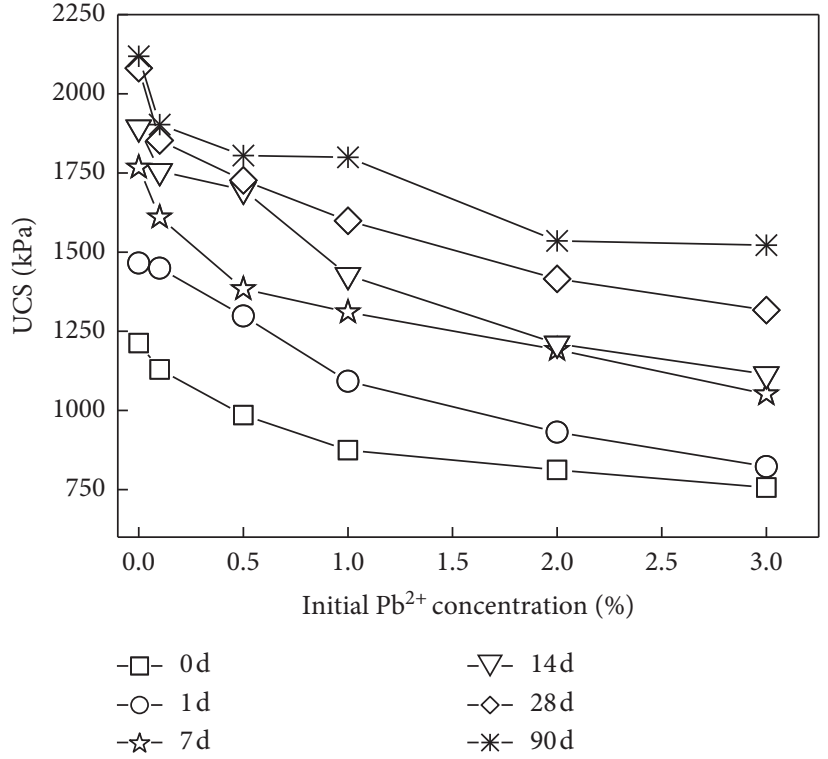

(a)

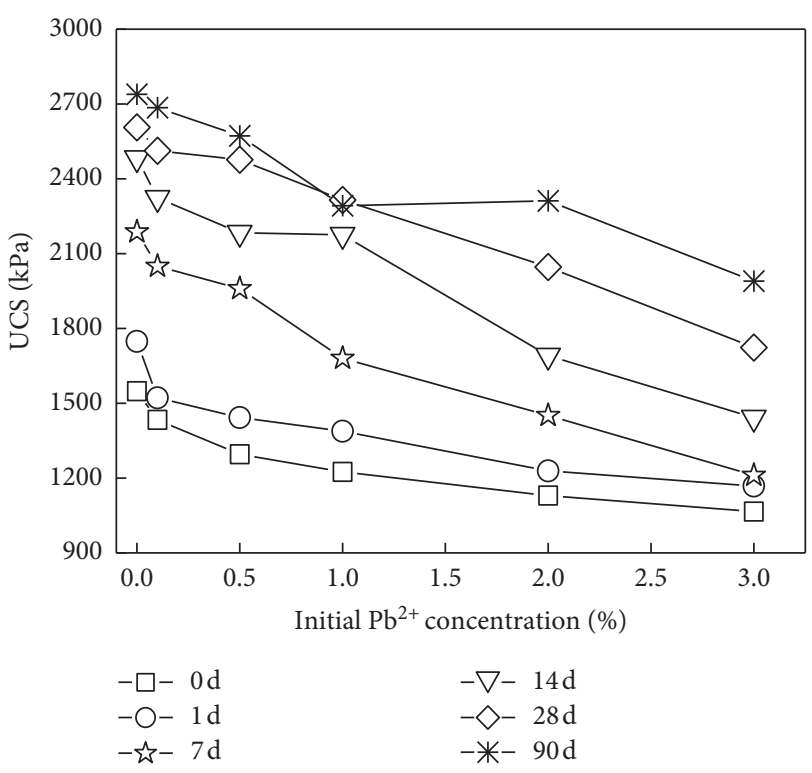

(b)

FIgUre 5: Evolutions of the UCS with the initial $\mathrm{Pb}^{2+}$ concentrations of the specimen. Alkaline residue contents of (a) $10 \%$ and (b) $30 \%$.

alkaline residue and the soil particles can be retarded owing to the existence of $\mathrm{Pb}^{2+}$, and then the generation of the hydration products will be decelerated $[9,21-23]$. Additionally, due to the alkaline environment created by the alkaline residue, $\mathrm{Pb}^{2+}$ will be involved in the hydration reactions resulting in generation of $\mathrm{Pb}$ complex and reduction of the hydration products. The $\mathrm{Pb}$-precipitation will also form in this alkaline environment and encapsulate the alkaline residue and soil particles, which prevent the further hydration reaction $[5,23]$.

\subsection{Effects on the Leaching Characteristic of the Solidified/} Stabilized Specimen. The leaching characteristics of the solidified/stabilized specimen are investigated with consideration of different influencing factors. The effects of the alkaline residue content on the leaching characteristics are typically shown in Figure 6.

As shown in Figure 6, the leached $\mathrm{Pb}^{2+}$ concentrations are extremely high when alkaline residue contents are at low ranges and will decrease with the increase of the alkaline residue content. Notable decreasing magnitude of $94 \%-98 \%$ can be observed at the alkaline residue content of $30 \%$ and curing time of $28 \mathrm{~d}$, which is of great importance to the engineering practice. This significant improvement of the leaching characteristic of the specimen is mainly attributed to the adsorption of $\mathrm{Pb}^{2+}$ by the generated hydration products [14]. Besides, $\mathrm{Pb}^{2+}$ could react with $\mathrm{OH}^{-}$and $\mathrm{CO}_{3}{ }^{2+}$ in such alkaline environment leading to the formation of precipitates with $\mathrm{Pb}^{2}$ ${ }^{+}$adsorbing on the particle surface. Moreover, $\mathrm{Pb}^{2+} \mathrm{can}$ partially replace $\mathrm{Ca}^{2+}$ in $\mathrm{CaO} \cdot \mathrm{SiO}_{2} \cdot n \mathrm{H}_{2} \mathrm{O}(\mathrm{C}-\mathrm{S}-\mathrm{H})$ and then be fixed in the reticular structure of silicate represented as C-Pb-S-H [21, 22, 24, 25].
The effects of the curing time on the leaching characteristics of the solidified/stabilized specimen are presented in Figure 7.

In Figure 7, the leached $\mathrm{Pb}^{2+}$ concentration decreases with the curing time increasing. Notable decreasing magnitude of $89 \%-98 \%$ can be observed before 28 -day curing at the alkaline content of $30 \%$. After this, the evolution of the leached $\mathrm{Pb}^{2+}$ concentration becomes stable until 90-day curing is reached. This is because the hydration process will be improved and fully developed with the curing time increasing. The hydration products like $\mathrm{CSH}$ will be generated and effectively immobile the $\mathrm{Pb}^{2+}$ in such high alkaline environment provided by alkaline residue, which contributes to the improvement of the leaching characteristics of the specimen. Based on this result, it can be concluded that the leaching characteristics of the specimen can be improved in a short time due to the existence of the alkaline residue.

One point should be paid attention in Figures 6 and 7 is that the leaching characteristics of the specimen are strongly dependent on the initial $\mathrm{Pb}^{2+}$ concentration in the specimen. For further analysis, the evolutions of the leached $\mathrm{Pb}^{2+}$ concentration with the initial $\mathrm{Pb}^{2+}$ concentration in the specimen are shown in Figure 8.

Results in Figure 8 suggest that the leached $\mathrm{Pb}^{2+}$ concentration is extremely high for the specimen with higher initial $\mathrm{Pb}^{2+}$ concentration and will increase with the increase of the initial $\mathrm{Pb}^{2+}$ concentration in the specimen, which is attributed to the retardation of the hydration process, as well as the limitation of the immobilized capacity, due to the existence of the $\mathrm{Pb}^{2+}$ in the specimen $[24,25]$.

3.3. Microstructure Analysis. For explanation of the strength and leaching characteristics of the solidified/stabilized 


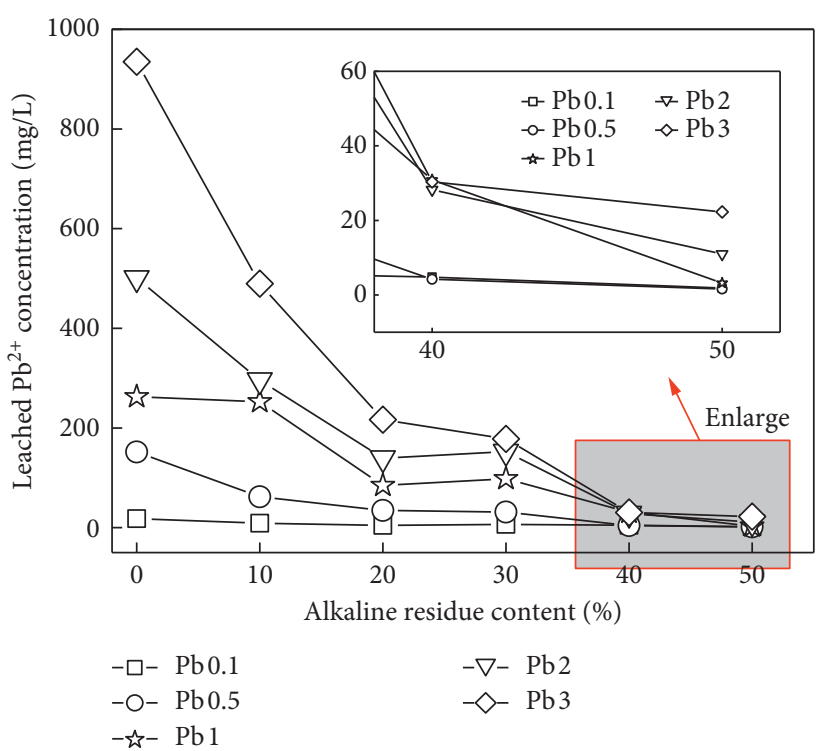

(a)

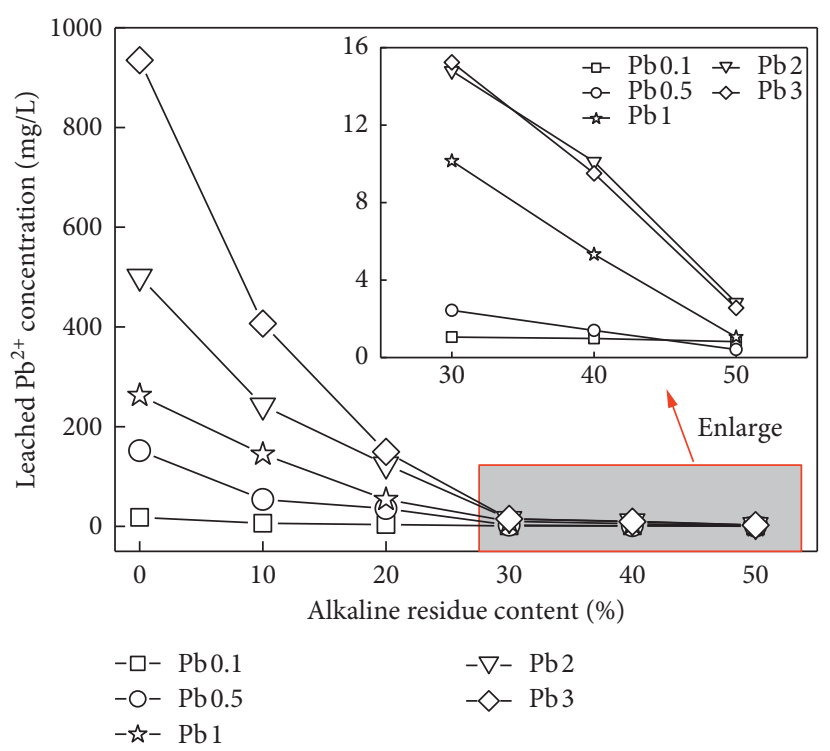

(b)

FIGURE 6: Evolutions of the leached $\mathrm{Pb}^{2+}$ concentration with the alkaline residue content of the specimen. Curing times of (a) $1 \mathrm{~d}$ and (b) $28 \mathrm{~d}$.

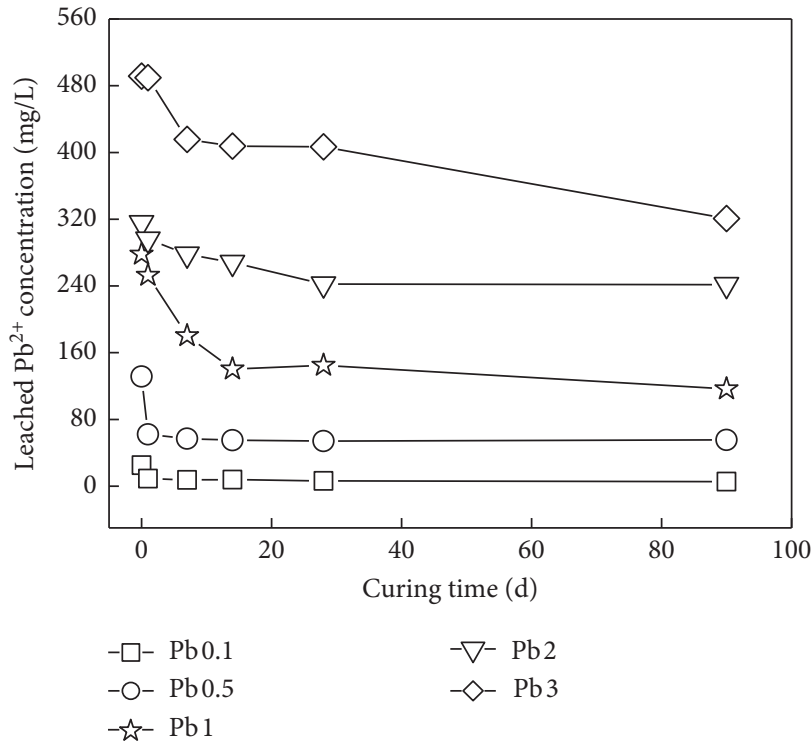

(a)

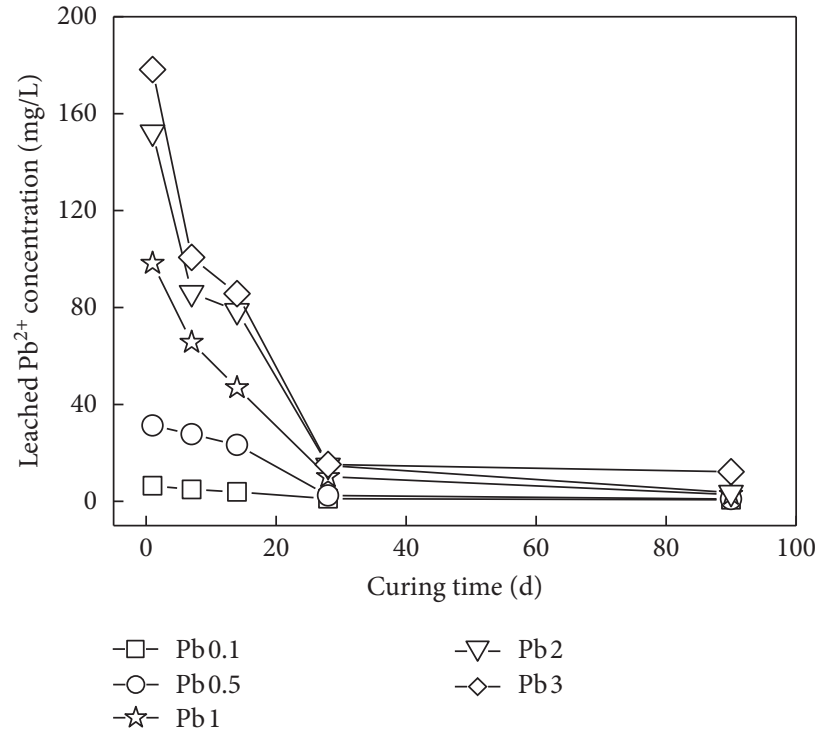

(b)

Figure 7: Evolutions of the leached $\mathrm{Pb}^{2+}$ concentration with the curing time of the specimen. Alkaline residue contents of (a) $10 \%$ and (b) $30 \%$.

specimens under different conditions (alkaline residue content, curing time, and initial $\mathrm{Pb}^{2+}$ concentration), the SEM technique is adopted to perform the microstructural analysis as shown in Figure 9.

As shown in Figure 9, hydration products like cottonlike C-S-H, calcite drusy, and portlandite are presented in the solidified/stabilized specimen due to the physicalchemical reactions between the alkaline residue and soil [26]. $\mathrm{Pb}^{2+}$ will be immobilized in C-S-H through physical adsorption/encapsulation and chemical single displacement reactions. $\mathrm{Ca}^{2+}$ contained in C-S-H will be substituted by $\mathrm{Pb}^{2+}$ resulting in the decrease of the strength and increase of the chemical connection between $\mathrm{Pb}^{2+}$ and hydration products. $\mathrm{Pb}-\mathrm{CSH}$ gel could be observed on the surface of the soil particles, which implies the effective immobilization of $\mathrm{Pb}^{2+}$ in the specimen $[27,28]$. Additionally, densification of the microstructure is clearly presented due to the massive formation of the hydration products. With the increase of alkaline residue content and curing time, the hydration process will be 


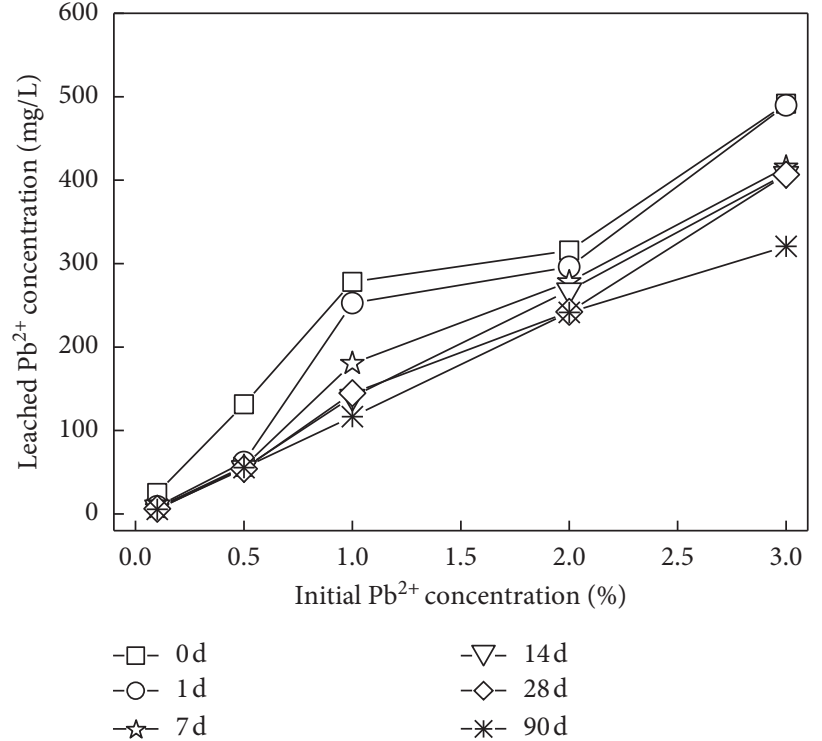

(a)

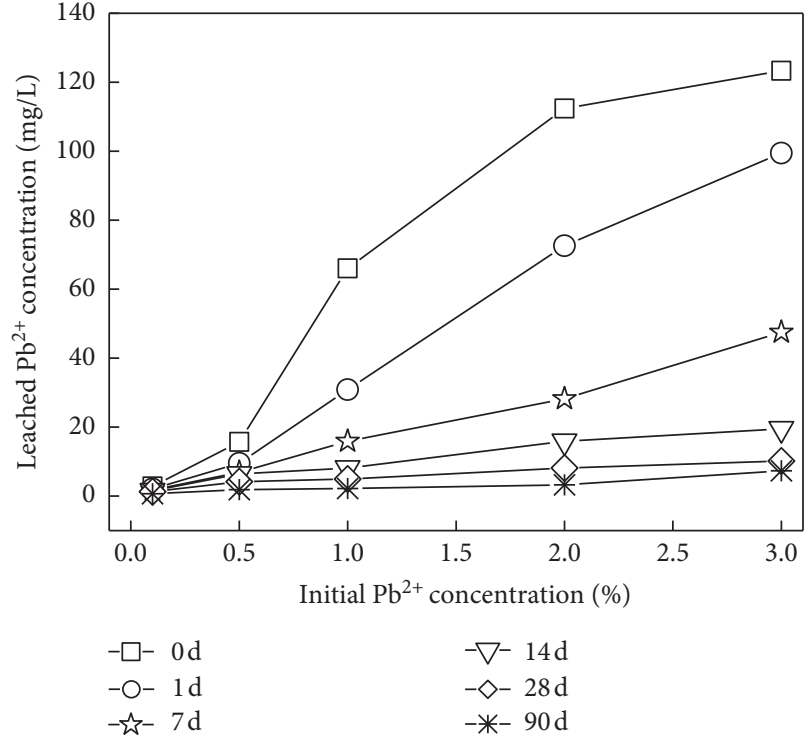

(b)

Figure 8: Evolutions of the leached $\mathrm{Pb}^{2+}$ concentration with the initial $\mathrm{Pb}^{2+}$ concentration of the specimen. Alkaline residue contents of (a) $10 \%$ and (b) $30 \%$.

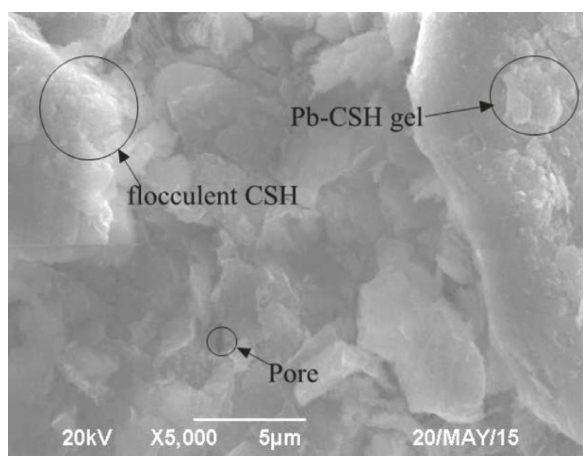

(a)

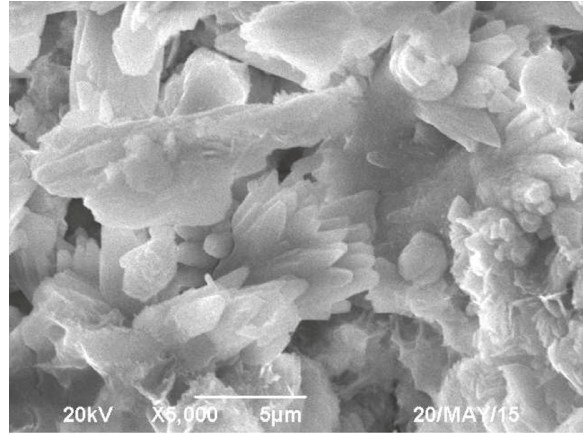

(c)

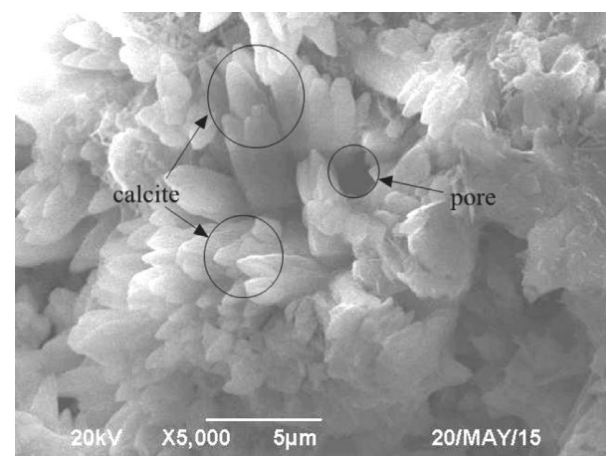

(b)

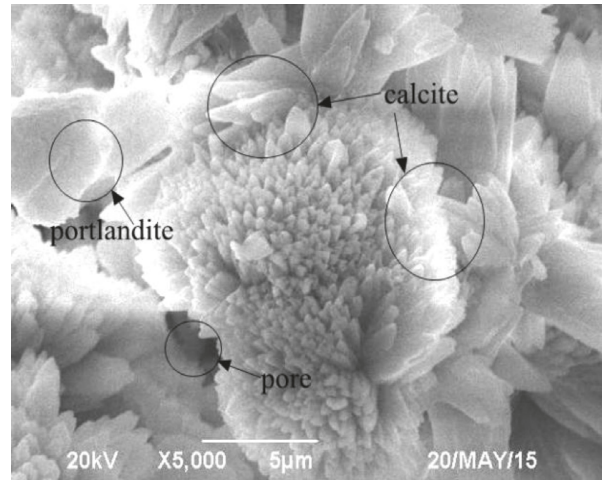

(d)

FIGURE 9: Microstructural characteristics of the specimens tested under different conditions. (a) AR10 + Pb1 (28 d). (b) AR30 + Pb1 (28 d). (c) AR30 + Pb3 (28 d). (d) AR30 + Pb1 (90 d).

promoted resulting in more hydration products. Based on these complicated physical-chemical reactions in the specimen, the strength and leaching characteristics will be effectively improved.

\section{Conclusions}

The strength and leaching characteristics, as well as the microstructural characteristic of the alkaline residue 
solidified/stabilized $\mathrm{Pb}$-contaminated soil, were experimentally investigated in the present work. Some main conclusions can be summarized as follows:

(1) The UCS of the treated specimen increased with the increase of the alkaline residue content. The UCS of the treated specimen increased with the curing time increasing. Notable increasing magnitude was observed at the early period of curing followed by a slight increase in the long curing period. The increase of the initial $\mathrm{Pb}^{2+}$ concentration in the specimen resulted in a notable decrease of the UCS.

(2) Leached $\mathrm{Pb}^{2+}$ concentration after the TCLP test decreased with the increase of the alkaline residue content and curing time, while increased with the increase of the initial $\mathrm{Pb}^{2+}$ concentration in the specimen. The higher initial $\mathrm{Pb}^{2+}$ concentration in the specimen will result in more notable increase of the leached $\mathrm{Pb}^{2+}$ concentration.

(3) Microstructural analysis performed by the SEM technique confirmed the existence of $\mathrm{CSH}$, calcite, portlandite, and other hydration products in the solidified/stabilized specimen. The amount of the hydration products, as well as the density and integrity of the specimen, increased with the increase of alkaline residue content and curing time.

\section{Data Availability}

The data used to support the findings of this study are available from the corresponding author upon request.

\section{Conflicts of Interest}

The authors declare that they have no conflicts of interest.

\section{Acknowledgments}

The authors are grateful to the National Natural Science Foundation of China (Project nos. 41672306 and 41372281).

\section{References}

[1] B. M. Sunil, S. Shrihari, and S. Nayak, "Shear strength characteristics and chemical characteristics of leachatecontaminated lateritic soil," Engineering Geology, vol. 106, no. 1-2, pp. 20-25, 2009.

[2] F. S. Zha, L. Xu, and K. R. Cui, "Strength characteristics of heavy metal contaminated soils stabilized/solidified by cement," Rock and Soil Mechanics, vol. 33, no. 3, pp. 652-656, 2012, in Chinese.

[3] S. L. Lin, W. H. Cross, E. S. K. Chian, J. S. Lai, M. Giabbai, and C. H. Hung, "Stabilization and solidification of lead in contaminated soils," Journal of Hazardous Materials, vol. 48, no. $1-3$, pp. $95-110,1996$

[4] M. A. Janusa, C. A. Champagne, J. C. Fanguy, G. E. Heard, P. L. Laine, and A. A. Landry, "Solidification/stabilization of lead with the aid of bagasse as an additive to Portland cement," Microchemical Journal, vol. 65, no. 3, pp. 255-259, 1998.
[5] C. Y. Jing, X. G. Meng, and G. P. Korfiatis, "Lead leachability in stabilized/solidified soil samples evaluated with different leaching tests," Journal of Hazardous Materials, vol. 114, no. 1-3, pp. 101-110, 2004.

[6] C-Y. Yin, H. B. Mahmud, and M. G. Shaaban, "Stabilization/ solidification of lead-contaminated soil using cement and rice husk ash," Journal of Hazardous Materials, vol. 137, no. 3, pp. 1758-1764, 2006.

[7] X. D. Li, C. S. Poona, H. Sun, I. M. C. Lo, and D. W. Kirk, "Heavy metal speciation and leaching behaviors in cement based solidified/stabilized waste materials," Journal of Hazardous Materials, vol. 82, no. 3, pp. 215-230, 2001.

[8] N. Bolan, A. Kunhikrishnan, R. Thangarajan et al., "Remediation of heavy metal(loid)s contaminated soils-to mobilize or to immobilize?," Journal of Hazardous Materials, vol. 266, pp. 141-166, 2014.

[9] Y. J. Du, M. L. Wei, K. R. Reddy, Z. P. Liu, and F. Jin, "Effect of acid rain $\mathrm{pH}$ on leaching behavior of cement stabilized leadcontaminated soil," Journal of Hazardous Materials, vol. 271, pp. 131-140, 2014.

[10] Q. Xue, P. Wang, J. S. Li, T. T. Zhang, and S. Y. Wang, "Investigation of the leaching behavior of lead in stabilized/ solidified waste using a two-year semi-dynamic leaching test," Chemosphere, vol. 166, pp. 1-7, 2017.

[11] Y. B. Yan, F. J. Qi, B. Seshadri et al., "Utilization of phosphorus loaded alkaline residue to immobilize lead in a shooting range soil," Chemosphere, vol. 162, pp. 315-323, 2016.

[12] X. Cao, C. J. Jin, X. C. Liu, and G. Peng, "Adsorption characteristics of copper ions on alkaline sludge," Environment Chemistry, vol. 25, no. 4, pp. 414-419, 2006, in Chinese.

[13] C. J. Jin, G. B. Tian, X. Cao, Z. L. She, and J. G. Zheng, "Adsorption characteristics of zinc ions on alkaline sludge," Chinese Journal of Environmental Engineering, vol. 9, no. 2, pp. 1218-1222, 2008, in Chinese.

[14] S. L. Sun, Q. H. Zheng, J. Tang et al., "Experimental research on expansive soil improved by Alkaline residue," Rock and Soil Mechanics, vol. 33, no. 6, pp. 1608-1612, 2012, in Chinese.

[15] F. Wang, Z. Q. Xu, L. X. Yan, and P. Cao, "Study on test methods and geotechnical properties of alkaline residue," Chinese Journal of Geotechnical Engineering, vol. 29, no. 8, pp. 1211-1214, 2007, in Chinese.

[16] The Professional Standards Compilation Group of People's Republic of China, JTGE 40-2007 Test Methods of Soils for Highway Engineering, China Communications Press, Beijing, China, 2007.

[17] S. K. Ouki and C. D. Hills, "Microstructure of Portland cement pastes containing metal nitrate salts," Waste Management, vol. 22, no. 2, pp. 147-151, 2002.

[18] D. I. Boardman, Lime stabilisation: clay-metal-lime interactions, Ph.D. thesis, Loughborough University, Loughborough, UK, 1999.

[19] ASTM, Standard Test Method for Unconfined Compressive Strength of Cohesive Soil, Annual Book of ASTM Standards D2166-06, American Society of Testing and Materials, West Conshohocken, PA, USA, 2000.

[20] US EPA, Toxicity Characteristic Leaching Procedure, Test Methods for Evaluating Solid Waste, Physical/Chemical Methods, SW-846, US EPA, Washington, DC, USA, 3rd edition, 1992.

[21] D. J. Lee, T. D. Waite, G. Swarbrick, and S. Lee, "Comparison of solidification/stabilization effects of calcite between Australian and South Korean cements," Cement and Concrete Research, vol. 35, no. 11, pp. 2143-2157, 2005. 
[22] D. J. Lee, "Formation of leadhillite and calcium lead silicate hydrate (C-Pb-S-H) in the solidification/stabilization of lead contaminants," Chemosphere, vol. 66, no. 9, pp. 1727-1733, 2007.

[23] L. Chen, S. Y. Liu, Y. J. Du, and F. Jin, "Unconfined compressive strength properties of cement solidified/stabilized lead-contaminated soils," Chinese Journal of Geotechnical Engineering, vol. 32, no. 12, pp. 1898-1903, 2010, in Chinese.

[24] M. S. Y. Bhatty, "Fixation of metallic ions in Portland cement," in Proceedings of 4th National Conference on Hazardous Wastes and Hazardous Materials, pp. 140-145, Washington, DC, USA, 1987.

[25] D. L. Cocke and M. Y. A. Mollah, "The chemistry and leaching mechanisms of hazardous substances in cementitious solidification/stabilization systems," in Chemistry of Microstructure Solidified Waste Forms, Lewis, Ann Arbor, MI, USA, 1993.

[26] J. Bensted and P. Barnes, Structure and Performance of Cements, Taylor \& Francis, Didcot, UK, 2nd edition, 2002.

[27] G. Thevenin and J. Pera, "Interactions between lead and different binders," Cement and Concrete research, vol. 29, no. 10 , pp. $1605-1610,1999$.

[28] N. Gineys, G. Aouad, and D. Damidot, "Managing trace elements in Portland cement-part I: interactions between cement paste and heavy metals added during mixing as soluble salts," Cement and Concrete Composites, vol. 32, no. 8, pp. 563-570, 2010. 


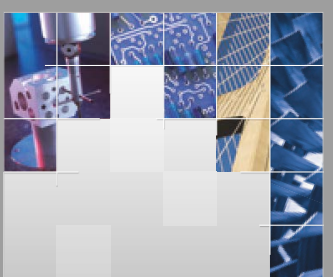

\section{Enfincering}
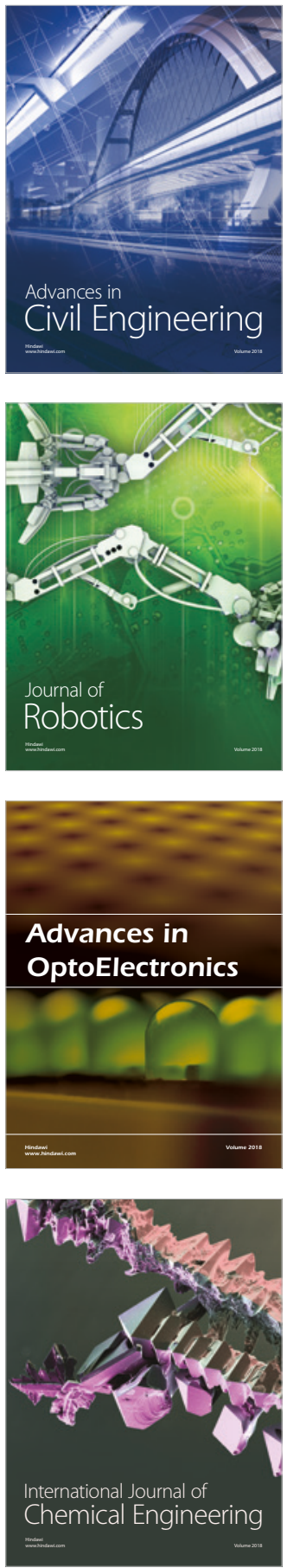

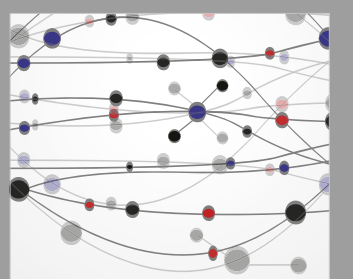

\section{Rotating \\ Machinery}

The Scientific World Journal

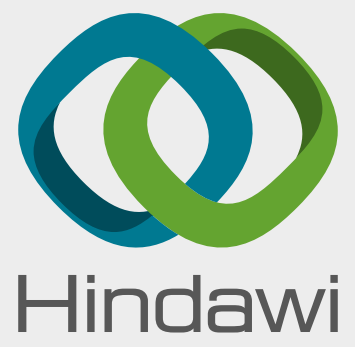

Submit your manuscripts at

www.hindawi.com
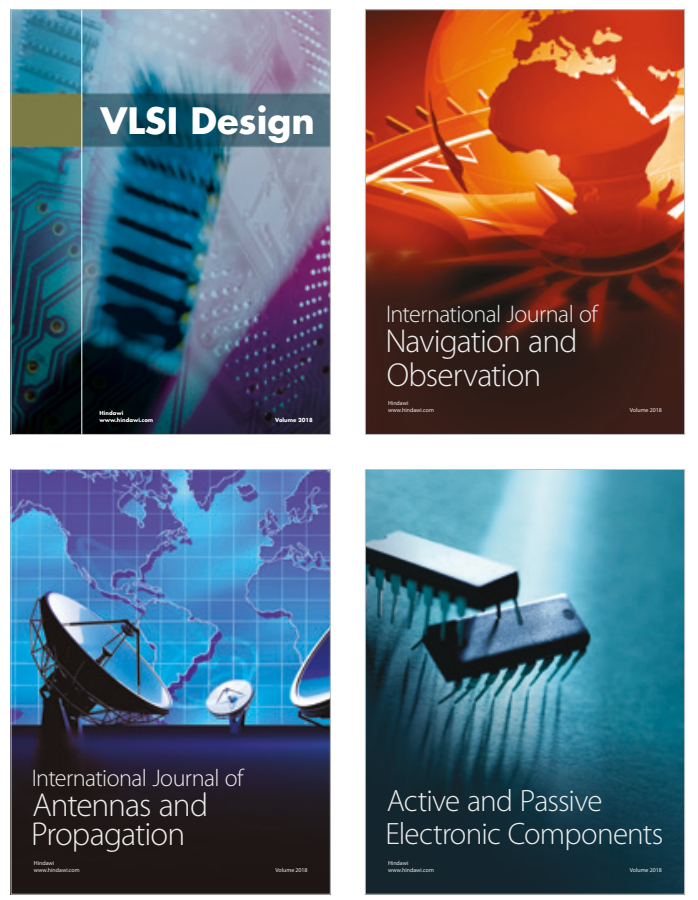
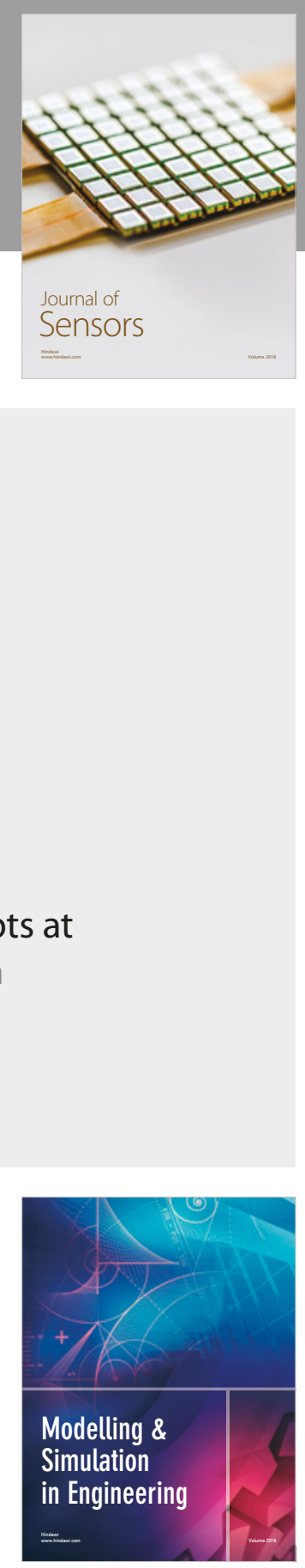

\section{Advances \\ Multimedia}
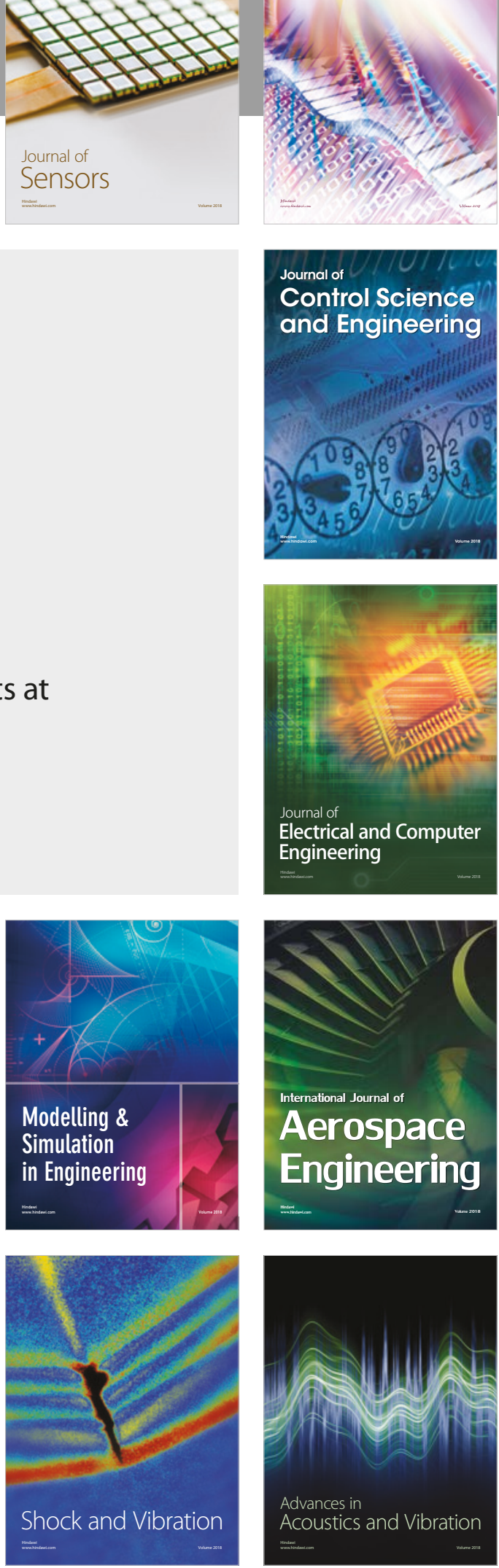